\title{
Sertão.Bit: Um Livro-Jogo de Difusão do Pensamento Computacional
}

\author{
Rozelma Soares de França ${ }^{1,2}$, Patrícia Cabral de Azevedo Restelli Tedesco ${ }^{1}$ \\ ${ }^{1}$ Centro de Informática - Universidade Federal de Pernambuco (UFPE) \\ 50740-560 - Recife - PE - Brasil \\ ${ }^{2}$ Departamento de Educação - Universidade Federal Rural de Pernambuco (UFRPE) \\ 52171-900 - Recife - PE - Brasil \\ \{rsf2, pcart\}@cin.ufpe.br
}

\begin{abstract}
Several challenges permeate computational thinking. One of them refers to teaching materials that support their implementation in schools and that consider the cultural context of students. In this context, this paper proposes a book-game to mediate the development of computational thinking in elementary school. The proposal uses the Pernambuco backlands as a scenario for the activities, building a bridge between the knowledge of Computing and Literature. Throughout the text, the proposed activities are presented, based on unplugged and plugged approaches.
\end{abstract}

Resumo. Diversos desafios permeiam o pensamento computacional. Um deles refere-se a materiais didáticos que deem suporte à sua implementação nas escolas e que considerem o contexto cultural dos estudantes. Neste contexto, este artigo propõe um livro-jogo para mediação do desenvolvimento do pensamento computacional no ensino fundamental. A proposta usa o sertão de Pernambuco como cenário para as atividades, construindo uma ponte entre os conhecimentos de Computação e Literatura. Ao longo do texto são apresentadas as atividades propostas, baseadas em abordagens desplugada e plugada.

\section{Introdução}

A computação está cada vez mais onipresente na sociedade sendo observado, nos últimos anos, diversas iniciativas de promoção do pensamento computacional, tais como Code.org e o Programaê, na educação básica. Além disso, alguns avanços foram feitos no campo da definição de currículos para fomentar competências computacionais; tendo alguns países a Computação no programa de suas escolas [Vicari et al. 2018]. Esforços como o projeto Computer Science Unplugged, que introduz conceitos de Computação sem o uso do computador, merecem destaque, uma vez que fornecem suporte à prática docente e consequente contato de crianças à natureza do pensamento computacional.

Apesar do exposto, a criação e acesso a materiais didáticos ainda é uma questão em aberto. Na pesquisa realizada Vicari et al. (2018) foram levantados materiais que apoiam o desenvolvimento do pensamento computacional na educação básica. Em relação aqueles ditos desplugados (sem uso do computador) e em português, os autores concluíram que o conjunto disponível ainda é limitado, com um número pequeno de materiais capaz de atender plenamente os critérios para o desenvolvimento do pensamento computacional. De forma complementar, o documento intitulado "Diretrizes para ensino de Computação na Educação Básica" proposto pela Sociedade Brasileira de Computação define habilidades de 
VIII Congresso Brasileiro de Informática na Educação (CBIE 2019)

Anais dos Workshops do VIII Congresso Brasileiro de Informática na Educação (WCBIE 2019)

Computação para os ensinos fundamental e médio, porém não fornece materiais que deem suporte ao desenvolvimento dessas habilidades. Ainda, apesar da importância do contexto sociocultural, ele ainda é pouco reconhecido e considerado em pesquisas sobre pensamento computacional [Ortiz et al. 2018].

Assim, tendo em vista a diversidade do contexto brasileiro, são necessários esforços de pesquisadores e educadores na produção de materiais didáticos situados no contexto e que apoiem o pensamento computacional na formação dos estudantes. É nessa direção que se situa este trabalho, vislumbrando a concepção de um livro-jogo com atividades fundamentadas nos pilares do pensamento computacional para o ensino fundamental. $\mathrm{O}$ trabalho usa o sertão pernambucano como cenário das lições, sendo seu enredo baseado em um livro infantil que conta a história de Virgulino Ferreira, o Lampião, quando criança. Com isso, a pesquisa estabelece laços com outros domínios, possibilitando promover a construção de conhecimentos de Computação e Literatura, construindo pontes entre essas duas áreas.

Além desta seção introdutória, este artigo está organizado da seguinte forma: a seção 2 apresenta concepções de pensamento computacional e ilustra sua aplicação em outras áreas, diferentes da Computação; a seção 3 traz exemplos de materiais didáticos que podem ser usados no desenvolvimento do pensamento computacional na escola; a seção 4 apresenta o livro-jogo sertão.bit, descrevendo seus objetivos e ilustrando atividades que o compõem. Por fim, a seção 5 tece algumas considerações finais acerca de todo o trabalho e planejamento de atividades futuras.

\section{Ressignificando o Pensamento Computacional}

Embora ainda não bem definido, há algum consenso sobre os aspectos fundamentais do pensamento computacional. Para Wing (2006), ele envolve resolver problemas, projetar sistemas e entender o comportamento humano, baseando-se nos conceitos fundamentais da Ciência da Computação. Já Selby e Woollard (2013), a partir de uma revisão de literatura, definem pensamento computacional como uma abordagem focada, mas não limitada, na solução de problemas, incorporando processos de pensamento que utilizam abstração, decomposição, algoritmo, avaliação e generalizações.

Com base em um estudo longitudinal, os resultados de Proctor e Blikstein (2018) sugerem que práticas socioculturais podem desempenhar um papel importante na aprendizagem dos princípios da Ciência da Computação. Assim, uma definição mais ampla que reconheça o pensamento computacional como um conjunto situado de práticas pode ser o mais útil. Isto está de acordo com Kafai (2016) ao reformular o pensamento computacional como participação computacional, onde os estudantes se envolvem em projetos autênticos, indo de ferramentas e códigos per si para a criação de projetos reais e tangíveis que podem ser compartilhados com outras pessoas.

Em consonância com esses trabalhos, Grover e Pea (2013) já haviam identificado que poucos estudos levavam em consideração a aprendizagem sociocultural e situada e a cognição distribuída em suas práticas de pensamento computacional na educação básica. Além disso, ressaltam que já na década de 1980 aspectos cognitivos de crianças durante a aprendizagem de conceitos computacionais foram estudados e tais resultados devem ser considerados na pesquisa contemporânea.

Embora o pensamento computacional possa ser promovido por meio da programação, ele não deve ser resumido a isso [Wing 2006]. Tendo em vista sua 
VIII Congresso Brasileiro de Informática na Educação (CBIE 2019)

Anais dos Workshops do VIII Congresso Brasileiro de Informática na Educação (WCBIE 2019)

possibilidade de aplicação em diferentes domínios, e não apenas na Computação, diversas iniciativas têm explorado seu caráter interdisciplinar. Em Ferreira et al. (2015) é reportada uma experiência de integração do pensamento computacional a conteúdos curriculares da educação básica. As intervenções foram baseadas em atividades sem o uso do computador, envolvendo disciplinas como Artes, Biologia, Química, Educação Física e Matemática em uma escola pública.

No YouTube, o canal AlgoRythmics explora didaticamente algoritmos, tais como os de ordenação Mergesort e Quicksort, a partir de dança folclórica europeia. O projeto é mantido por colaboradores da Romênia, trazendo a dança como uma distinta forma de promover a educação em Computação. Mais recentemente, o The New York Times (2019) publicou uma matéria em que demonstra como tricotar pode ser entendido como um processo de codificação; e o fio, um material programável. Esses são somente alguns exemplos que demonstram como o pensamento computacional pode ser explorado em outras áreas para resolver problemas e descobrir novas questões, não encerrando sua aplicação àquelas aqui relatadas.

\section{Materiais Didáticos: de Plugados a Desplugados}

Os materiais usados em práticas de desenvolvimento de pensamento computacional na educação básica podem ser classificados em duas categorias: i) plugados, que requerem máquina para seu uso; e ii) desplugados; que independem de máquina para promover o ensino de Computação. Em relação aos plugados, eles se apresentam de diferentes maneiras, dentre elas: jogos, ambientes de programação visual, brinquedos programáveis e kits de robótica. Nesse contexto, identificou-se no levantamento realizado que o LightBot é um dos jogos comumente reportados em experiências de ensino de Computação. Nele, o estudante deve programar o movimento de um robô virtual utilizando um conjunto de instruções gráficas disponíveis no jogo. Ainda pode-se citar o Move the Turtle e o Run Marco com características similares ao LightBot.

Utilizando como abordagem blocos de comandos que se encaixam uns aos outros, como um quebra-cabeça, estão os ambientes de programação visual. Neles, o estudante pode dedicar seu esforço cognitivo à lógica de funcionamento do projeto, sem se preocupar com a sintaxe de uma linguagem de programação específica. Scratch, App Inventor e Kodu são exemplos desse tipo de ambiente. Em relação aos brinquedos programáveis identificouse que, em geral, possuem botões que representam as direções e a trajetória que o brinquedo deve seguir a partir de uma sequência de instruções dada pelo estudante. O Bee-Bot, o RoPE e o Cubetto podem ser citados nessa dimensão. No que diz respeito aos kits de robótica, eles possibilitam o trabalho com a programação em diferentes níveis de abstração, a depender do modelo. Exemplos incluem o Lego Mindstorms NXT e o Micro:bit.

Das iniciativas desplugadas, o Computer Science Unplugged [Bell et al. 2011] encabeça a lista. O livro está disponível gratuitamente em diferentes idiomas, dentre eles o Português, e cobre diferentes tópicos da Computação, como números binários, representação de imagens nos computadores, algoritmos de busca e ordenação e criptografia. Outro projeto que se pode mencionar é o Hello Ruby de Linda Liukas, que provê em seus livros histórias de aventura e atividades que incorporam conceitos computacionais. Atualmente, somente o livro que aborda lógica da programação possui tradução para o Português.

No Brasil, Brackmann (2017) propôs atividades desplugadas com personagens da Turma da Mônica que exploram os pilares do pensamento computacional. Outro caso 
VIII Congresso Brasileiro de Informática na Educação (CBIE 2019)

Anais dos Workshops do VIII Congresso Brasileiro de Informática na Educação (WCBIE 2019)

identificado envolve a Universidade de Santa Cruz do Sul (UNISC) por meio do Projeto Unisc Inclusão Digital, o qual possibilitou a elaboração de materiais didáticos desplugados, disponíveis em seu site. Também, há os Almanaques para Popularização da Ciência da Computação em formato de histórias em quadrinhos que nas últimas edições apresenta-se como guia de atividades para exploração do pensamento computacional. Uma série de livros intitulada Computação Fundamental também tem sido desenvolvida, tendo sido publicados os guias para o $6^{\circ}$ e $7^{\circ}$ anos do ensino fundamental. Apesar de reconhecer o mérito dessas iniciativas, para além de promover o acesso ao pensamento computacional, busca-se propor nesta pesquisa atividades situadas no contexto cultural dos estudantes, como estratégia de engajá-los nesse processo e promover sua aprendizagem.

\section{Sertão.Bit: Conectando o Pensamento Computacional à Literatura}

Dada a necessidade do pensamento computacional na educação básica, sua natureza interdisciplinar e o conjunto limitado de materiais que podem apoiar o seu desenvolvimento, especialmente em Português e que considerem o contexto sociocultural, o sertão.bit foi concebido, tendo como público o ensino fundamental.

Seu enredo é baseado em A história de Lampião Júnior e Maria Bonitinha de Alves (2009). Na obra, a autora utiliza-se da licença poética que textos infantis possibilitam e narra a história de Virgulino Ferreira, o Lampião, em sua infância. O texto faz referência a diferentes situações nas quais Lampião Júnior e sua turma se envolvem em busca de uma solução para o sertão pernambucano sobreviver à profecia de virar mar.

Em sertão.bit: um livro-jogo de difusão do pensamento computacional, tal profecia embasa as lições e o leitor deve ajudar Lampião Júnior e sua turma a terem sucesso nessa jornada. Alguns episódios foram adaptados da história original e outros, criados, possibilitando o trabalho com os pilares do pensamento computacional. As lições propostas não se tratam só de programação. Algoritmos embasam algumas delas, mas abstração, decomposição e reconhecimento de padrões também são explorados. Além disso, boa parte dos exemplos do livro pode ser aplicada na resolução de problemas do dia a dia, tais como encontrar o par de uma meia em um amontoado de meias; localizar uma sala mais rapidamente, em um conjunto de dezenas de salas; identificar a melhor rota em um trajeto, dentre outros.

Cada lição apresenta uma situação-problema envolvendo Lampião Júnior. Sugere-se que elas sejam resolvidas na sequência em que estão organizadas, pois o enredo de cada lição complementa as ideias apresentadas na lição anterior. À medida em que for lendo o livro, o leitor poderá identificar elementos do folclore, dança e música nacionais. E, no final, poderá expressar sua identidade nesta aventura pelo sertão, escolhendo uma trajetória para criar, dentre as três sugeridas. Esse processo de criação envolve a elaboração de xilogravura ${ }^{1}$ e de códigos como expressão de sua criatividade.

\subsection{Estrutura do Livro-Jogo}

O sertão.bit começa apresentando um diálogo entre Lampião Júnior e seu avô em um dia chuvoso no sertão pernambucano. Se por um lado aquela chuva trazia gotas de esperança à seca que assolava a região, por outro remetia à profecia de Padim Ciço do Juazeiro que disse que, um dia, o sertão iria virar mar. Entre uma conversa e outra e sob a benção de seu avô e

\footnotetext{
${ }^{1}$ Xilogravura consiste na arte e técnica de fazer gravuras em relevo sobre madeira. Neste trabalho, é proposto que os estudantes executem a tarefa em isopor ou E.V.A.
} 
VIII Congresso Brasileiro de Informática na Educação (CBIE 2019)

Anais dos Workshops do VIII Congresso Brasileiro de Informática na Educação (WCBIE 2019)

proteção de seus santos de devoção, Lampião Júnior decide partir em busca de cumprir sua promessa: evitar que o sertão vire mar. É neste momento que iniciam as lições do livro-jogo e o estudante deve ajudar Lampião Júnior a cumpri-las da maneira mais eficiente. O Quadro 1 apresenta a sumarização das atividades, destacando seu tipo (desplugada ou plugada) e componentes de pensamento computacional explorados.

Quadro 1. Visão geral das atividades do sertão.bit

\begin{tabular}{|c|c|c|c|c|c|}
\hline \multirow[b]{2}{*}{ Atividade } & \multirow[b]{2}{*}{ Tipo } & \multicolumn{4}{|c|}{ Componentes Pensamento Computacional } \\
\hline & & Abstração & Decomposição & $\begin{array}{l}\text { Reconhecimento } \\
\text { de Padrões }\end{array}$ & Algoritmo \\
\hline A pareia da meia & $\ddot{\varphi}$ & $\mathrm{X}$ & $\mathrm{X}$ & $\mathrm{X}$ & $\mathrm{X}$ \\
\hline Trio desafinado & T & $\mathrm{X}$ & & $\mathrm{X}$ & $\mathrm{X}$ \\
\hline $\begin{array}{l}\text { Um poema para Maria } \\
\text { Bonitinha }\end{array}$ & i & $X$ & $\mathrm{X}$ & $\mathrm{X}$ & \\
\hline Disputa do xaxado & T & $\mathrm{X}$ & $\mathrm{X}$ & $\mathrm{X}$ & $\mathrm{X}$ \\
\hline Mandacaru matemático & 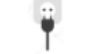 & $\mathrm{X}$ & & $\mathrm{x}$ & \\
\hline Criaturas do mato & $\ddot{\varphi}$ & $X$ & $\mathrm{X}$ & $X$ & $\mathrm{X}$ \\
\hline Rota do cangaço & $\ddot{\varphi}$ & $\mathrm{X}$ & $\mathrm{X}$ & & $x$ \\
\hline Repartir para achar & $\ddot{q}$ & $X$ & $\mathrm{X}$ & & \\
\hline $\begin{array}{l}\text { O labirinto de } \\
\text { Lampiãozinho }\end{array}$ & i & $X$ & & & $\mathrm{X}$ \\
\hline Salvo pelo algoritmo & 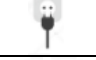 & $X$ & $x$ & $X$ & $X$ \\
\hline Eu autor & 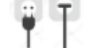 & $X$ & $x$ & $\mathrm{X}$ & $X$ \\
\hline
\end{tabular}

$\mathrm{Na}$ primeira lição, intitulada "A pareia da meia", fala-se que, antes de partir, Lampião Júnior foi ao quarto da casa de seu avô vestir uma roupa confortável para sair em peregrinação em busca de uma solução para salvar o sertão. Dentre as peças que ele desejava vestir estavam as meias. Ansioso pela partida, o garoto abriu o guarda-roupas, puxou o gaveteiro e derrubou todas as meias no chão. A pilha de meias era formada por diferentes pares e tamanhos. Ali estavam tanto as meias de Lampião Júnior, quanto as de seu avô, tornando a busca e a combinação de pares de meias mais demoradas do que ele imaginava. Uma ilustração desse cenário pode ser vista na Figura 1a.

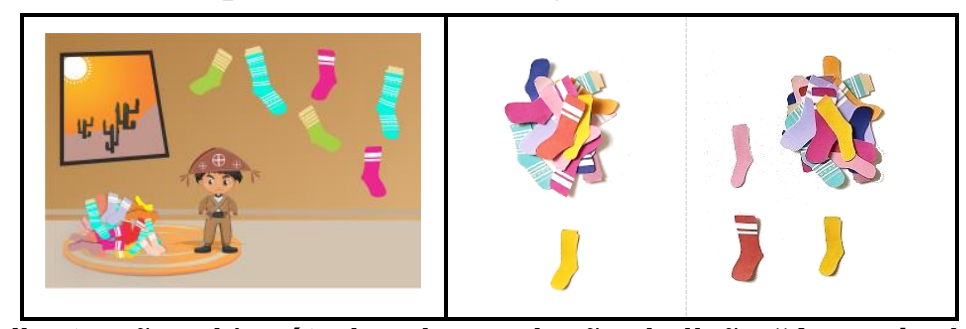

Figura 1. a) llustração e b) métodos de resolução da lição "A pareia da meia"

Neste momento é dado ao leitor a missão de ajudar Lampião Júnior a enfrentar a difícil tarefa de combinar, eficientemente, os pares de meias da pilha formada. Não basta escolher e combinar o par de meias que ele irá usar. Como ele derrubou tudo no chão, terá que combinar todos os pares, antes de sua partida, para que seu avô não fique chateado. Segue-se sugerindo que o leitor use as meias recortadas, disponibilizadas junto ao livro-jogo, 
VIII Congresso Brasileiro de Informática na Educação (CBIE 2019)

Anais dos Workshops do VIII Congresso Brasileiro de Informática na Educação (WCBIE 2019)

e faça as combinações de acordo com as cores e tamanhos. Ainda, pede-se que o leitor apresente dois métodos que poderiam ser usados por Lampião Júnior para achar o par de cada meia e que depois avalie os métodos usados e informe qual deles foi mais eficiente.

Nessa atividade, pode-se explorar o pilar abstração, uma vez que o estudante deverá ignorar a tarefa de separar meias das demais peças de roupa que ele iria usar; e focar na tarefa fundamental de combinar pares de meias. Decomposição também é passível de ser explorado, já que ele terá que fazer as combinações par a par. O reconhecimento de padrões também pode ser abordado, uma vez que é necessário fazer a combinação por cores e pelo tamanho das meias. Ainda, algoritmos é outro pilar trabalhado, tendo o estudante que apresentar dois métodos de resolução do problema, combinado à avaliação dos algoritmos por ele definidos.

Baseado em Almossawi (2017), como solução, o estudante poderia apresentar os seguintes métodos, demonstrados também na Figura $1 \mathrm{~b}$ :

- Método 1: Escolher uma meia da pilha. Tirar outra meia aleatoriamente para ver se combinam. Se sim, colocar as duas juntas ao lado. Se não, colocar a segunda meia de volta à pilha e puxar mais uma aleatoriamente. E assim continuar até encontrar o par correspondente de todas elas.

- Método 2: Escolher uma meia e colocá-la de um lado. Escolher outra meia e compará-la com a primeira. Se corresponder, fazer a combinação. Caso contrário, colocá-la ao lado da outra. E assim por diante, formando os pares por cores e tamanhos.

Se a pilha tiver quatro pares de meias, por exemplo, não haverá tanta diferença entre um método e outro. Contudo, se o número de pares aumentar, o método 2 pode ser mais rápido, devido à sua dependência da memória: o segundo método mantém uma linha de meias incomparáveis, garantindo assim que Lampião Júnior só encontre uma meia na pilha uma vez; diferente do primeiro método em que ao devolver a meia à pilha ele terá chance de pegar essa meia várias outras vezes.

Resolvido o desafio, o leitor está apto à continuação da história e resolução da lição seguinte. A lição 2 foi intitulado de "Trio desafinado". Nela, o leitor deve localizar um erro em um trecho de código de um projeto Scratch e fazer a correção, de modo que a música Asa Branca seja tocada corretamente. Baseada na atividade "Compressão de Texto" de Bell et al. (2011), a lição 3 pede que o leitor complete um poema a ser recitado por Lampião Júnior a Maria Bonitinha. De forma complementar, pede que o leitor elabore a resposta de Maria Bonitinha a Lampião Júnior. Para isso ele deve fazer uma estrofe de seis versos onde o segundo, o quarto e o sexto versos rimam entre si, deixando órfãos o primeiro, terceiro e quinto versos. Segundo a Academia Brasileira de Literatura de Cordel (s.d.) essa técnica é chamada de sextilha e percebe-se nela um potencial para se abordar principalmente o reconhecimento de padrões. É sugerido também que o estudante construa seu próprio enigma para o seu colega decifrar o poema criado.

A lição 4, denominada "Disputa do xaxado", simula um duelo entre Lampião Júnior e Corisquinho onde quem dançar melhor xaxado, ganha. Esta atividade integra recursos físicos e digitais: foi construído um tapete, como material complementar do livro-jogo, para que o leitor interaja com um projeto Scratch por meio de um kit que transforma objetos cotidianos em interfaces touchpads. A disputa é feita entre dois estudantes: um representa o Lampião e o outro, o Corisquinho. Cada um deve memorizar a sequência de passos que 
VIII Congresso Brasileiro de Informática na Educação (CBIE 2019)

Anais dos Workshops do VIII Congresso Brasileiro de Informática na Educação (WCBIE 2019)

simula o xaxado, apresentada na tela do computador, e reproduzi-la, movendo seus pés sobre o tapete. Essa proposta é baseada no jogo Genius que estimula a memorização de cores e sons. À medida em que vai interagindo e reproduzindo os passos corretamente, vai pontuando. Ganha quem concluir mais níveis.

Dentre os personagens da história, está Cacne, um mandacaru. E é a partir dele que a lição 5 foi construída. É proposto que o leitor observe a imagem de Cacne (Figura 2a) e tente identificar algum padrão em sua forma. Após ser apresentado ao conceito e exemplo de fractal, é proposto também que ele identifique a parte que está se repetindo em outra imagem e que use essa parte, desenhando-a quantas vezes forem necessárias até chegar no resultado demonstrado na Figura $2 b$.

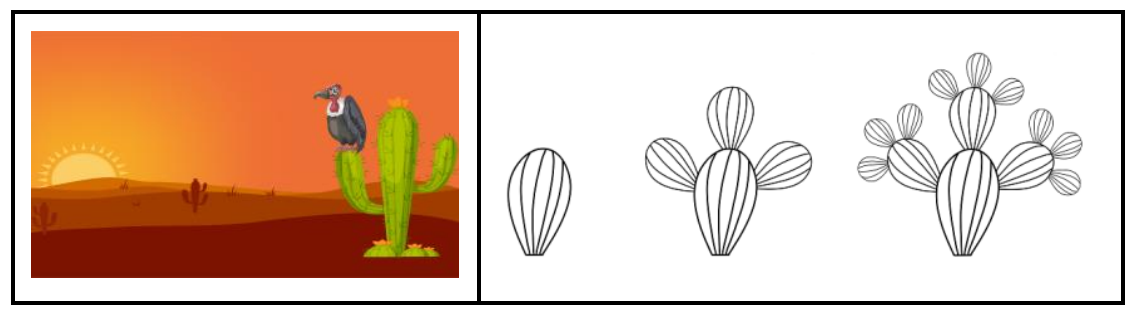

Figura 2. a) llustração e b) lição "Mandacaru matemático"

Dando continuidade à história, os pilares do pensamento computacional são base também para as lições seguintes. Devido a restrições de espaço, não será possível detalhar todas as atividades, mas em resumo: a lição 6 requer a identificação de padrões e criação de algoritmos para formação de criaturas do mato (saci pererê, mula sem cabeça, dentre outros); a lição 7 aborda a identificação do melhor trajeto entre Serra Talhada e Recife, conduzindo Lampião e sua turma ao escritório de um político; a lição 8 envolve a proposição de métodos para localização da sala de Logaritmo Fernandes, o político que eles tanto procuravam; na lição 9 o estudante deve conduzir Lampiãozinho em um labirinto, levando-o até o poço sem ser visto por capangas; na lição 10 é proposto um jogo para conduzir Iara até a borda do açude, levando Lampiãozinho até Maria Bonitinha.

Por fim, na lição 11, intitulada "Eu autor", é dada a oportunidade do leitor contribuir com a história. Para tanto, ele deve escolher uma das promessas feitas pelo político a Lampião Júnior e programar sua execução no Scratch. Antes disso, contudo, ele deve definir o enredo da cena, planejar ações que devem ser feitas em seu projeto Scratch, criar um cenário usando xilogravura em isopor ou E.V.A para servir como plano de fundo do projeto e dar vida à história codificando as ações planejadas.

\subsection{Aprendizagem Mediada}

A proposta deste livro-jogo considera que as interações sociais desempenham papel fundamental no desenvolvimento do pensamento computacional. Assim, o livro aparece como instrumento e sua ação é melhor consolidada com a mediação dos pares. Nesse sentido, o professor é figura fundamental, o qual também conta com um documento guia que poderá nortear o seu fazer pedagógico. Além disso, algumas lições foram intencionalmente elaboradas para favorecer a interação entre os estudantes. De modo complementar, scaffolds ${ }^{2}$ foram planejados como forma de ajudar o estudante na resolução das lições. Tal elemento

\footnotetext{
${ }^{2}$ Fundamentalmente a ideia de scaffold baseia-se na teoria de Vygotsky, sobre a Zona de Desenvolvimento Proximal. O objetivo é ajudar o aprendiz a fazer uma ponte entre o que ele sabe e o que ele pretende aprender, a partir de modelos e orientações.
} 
VIII Congresso Brasileiro de Informática na Educação (CBIE 2019)

Anais dos Workshops do VIII Congresso Brasileiro de Informática na Educação (WCBIE 2019)

aparece representado no livro por meio de uma lagartixa, que faz referência a Alan Turing, o pai da Ciência da Computação. Na apresentação do livro é sugerido que, em caso de dúvida, o leitor recorra a esse apoio, acessando a seção chamada "Conselho de Turing" de cada lição. No que diz respeito à estruturação das atividades, é usada a progressão de três etapas "usar-modificar-criar" para ajudar o estudante a avançar de usuário até criador de artefatos computacionais [Lee et al. 2011]. Nas atividades que envolvem modificação, elas foram intencionalmente planejadas para que o estudante tente abstrair partes irrelevantes do código e foque nas estruturas computacionais que se deseja que ele aprenda naquela etapa.

O sertão.bit não é somente físico e seu formato misto busca explorar diferentes estratégias para o desenvolvimento do pensamento computacional. Em um primeiro momento, são propostas atividades sem o uso do computador para que o leitor se familiarize com os conceitos fundamentais da computação, formulando e testando seus algoritmos. É neste momento que ele poderá analisar o problema e concentrar-se no procedimento passo a passo para sua solução, sem se preocupar com quaisquer regras de sintaxe. Esta decisão foi tomada para que o estudante pense no que está fazendo, ao invés de tentar resolver somente no modo de tentativa e erro. Em um segundo momento, atividades desplugadas e plugadas são propostas, tendo estas últimas um enfoque na modificação, como estratégia para apreensão de habilidades específicas. Na última etapa, o leitor é convidado a formular e testar seus algoritmos, convertendo-os em código executável no ambiente Scratch e observar sua execução. A xilogravura aparece como expressão criativa do estudante, podendo tornar o projeto mais significativo para ele, que também tomou a decisão de qual ação programar.

\subsection{Recursos Complementares}

Além do livro-jogo per si, alguns materiais foram planejados para complementar as lições. $\mathrm{Na}$ lição que trata da combinação dos pares de meias, por exemplo, o estudante pode manipular miniaturas dos pares de meias e fazer as combinações, testando seus métodos. Boa parte das lições pode ser realizada sem o uso do computador e os materiais tangíveis, como o descrito, poderão tornar a interação mais lúdica. Outras requerem um computador com acesso à internet e o ambiente de programação visual Scratch. Além disso, para complementar a interação, há lições que requerem o uso de um kit que transforma objetos cotidianos em interfaces touchpads, tais como o Makey Makey. Considera-se, assim, que a disponibilidade desses manipuladores físicos influencia a maneira como os estudantes usam o livro-jogo e como eles desenvolvem estratégias conceituais de compreensão de habilidades de pensamento computacional.

\section{Considerações Finais}

$\mathrm{O}$ pensamento computacional tem sido foco crescente de pesquisas nacionais e internacionais, visando sua implementação desde a educação básica. No entanto, ainda são muitas as questões em aberto. Uma delas diz respeito à elaboração de materiais didáticos, especialmente que considerem o contexto sociocultural dos estudantes.

No Brasil, apesar dos esforços para sua integração no currículo escolar, as políticas públicas não têm acompanhado as intenções da comunidade interessada do tema. Não surpreende, a literatura revela uma limitação de materiais didáticos, em Português, capazes de atender plenamente os pilares do pensamento computacional. Nesse contexto, este trabalho apresenta o sertão.bit, um recurso que explora o pensamento computacional aliado à literatura. O livro-jogo integra atividades desplugadas e plugadas e propõe diferentes modos de interação com os pilares do pensamento computacional, desde o uso até a criação. 
VIII Congresso Brasileiro de Informática na Educação (CBIE 2019)

Anais dos Workshops do VIII Congresso Brasileiro de Informática na Educação (WCBIE 2019)

Além disso, o enredo das atividades é pautado no contexto cultural dos estudantes, como estratégia para engajá-los e tornar a aprendizagem mais significativa.

Acompanhado à proposta de atividades estão as sequências didáticas que poderão nortear o fazer pedagógico de outros educadores interessados na temática. Para sua disponibilização na integra, experimentos estão sendo executados visando a avaliação das atividades e seus recursos associados. Tendo em vista que o sertão.bit propõe uma abordagem mista de ensino (desplugada e plugada), tem-se buscado identificar seu impacto sobre a aprendizagem dos estudantes, em comparação com uma abordagem totalmente desplugada. O entendimento de como eles interagem com esses recursos é necessário, uma vez que poderá influenciar a construção de novos materiais de apoio ao pensamento computacional.

\section{Agradecimentos}

As autoras agradecem a Paulo Ricardo B. Silva pela ilustração do livro-jogo sertão.bit.

\section{Referências}

Academia Brasileira de Literatura de Cordel. Disponível em $<$ http://www.ablc.com.br/ocordel/metricas-2/>. Acesso em 30 de set. 2019.

Almanaques para Popularização da Ciência da Computação. Disponível em $<\mathrm{http}$ ://almanaquesdacomputacao.com.br/gutanunes/publication.html/>. Acesso em 30 de set. 2019.

Almossawi, A. (2017). Bad Choices. Online edition. October 2017.

Alves, J. C. (2009). A história de Lampião Júnior e Maria Bonitinha. Bonobo Kids.

App Inventor. Disponível em $<$ https://appinventor.mit.edu/>. Acesso em 30 de set. 2019.

Bee-Bot. Disponível em <http://www.bee-bot.co.uk>. Acesso em 30 de set. 2019.

Bell, T., Witten, I. H., Fellows. (2011). Ensinando Ciência da Computação sem o uso do computador. Computer Science Unplugged.

Brackmann, C. P. (2017). Desenvolvimento do pensamento computacional através de atividades desplugadas na educação básica. Tese de doutorado.

Code.org. Disponível em < https://code.org/>. Acesso em 30 de set. 2019.

Computação $\quad$ Fundamental. Disponível em $<$ https://sites.google.com/view/computacaofundamental/>. Acesso em 30 de set. 2019.

Computer Science Unplugged. Disponível em $<$ http://csunplugged.org/>. Acesso em 30 de set. 2019.

Cubetto. Disponível em <https://www.primotoys.com/>. Acesso em 30 de set. 2019.

Ferreira, A. C., Melhor, A., Barreto, J., de Paiva, L. F., \& Matos, E. (2015). Experiência prática interdisciplinar do raciocínio computacional em atividades de computação desplugada na educação básica. In: Anais do Workshop de Informática na Escola (Vol. 21, No. 1, p. 256).

Grover, S., \& Pea, R. (2013). Computational thinking in K-12: A review of the state of the field. Educational researcher, 42(1), 38-43. 
VIII Congresso Brasileiro de Informática na Educação (CBIE 2019)

Anais dos Workshops do VIII Congresso Brasileiro de Informática na Educação (WCBIE 2019)

Hello Ruby. Disponível em <http://www.helloruby.com//>. Acesso em 30 de set. 2019.

Kafai, Y. B. (2016). From computational thinking to computational participation in K-12 education. Communications of the ACM, 59(8), 26-27.

Kodu. Disponível em <https://www.kodugamelab.com/>. Acesso em 30 de set. 2019.

Lee, I., Martin, F., Denner, J., Coulter, B., Allan, W., Erickson, J., \& Werner, L. (2011). Computational thinking for youth in practice. Acm Inroads, 2(1), 32-37.

Lego Mindstorms NXT. Disponível em $<$ https://www.lego.com/pt-br>. Acesso em 30 de set. 2019.

LightBot. Disponível em < http://lightbot.com/index.html>. Acesso em 30 de set. 2019.

Micro:bit. Disponível em <https://microbit.org/> . Acesso em 30 de set. 2019.

Move the Turtle. Disponível em <http://movetheturtle.com/> Acesso em 30 de set. 2019.

Ortiz, J. S. B., Moreira, C., \& Pereira, R. (2018). Aspectos do Contexto Sociocultural dos Alunos estão Presentes nas Pesquisas para Ensinar Pensamento Computacional?. In: Anais dos Workshops do VII Congresso Brasileiro de Informática na Educação.

Proctor, C., \& Blikstein, P. (2018). How Broad is Computational Thinking? A Longitudinal Study of Practices Shaping Learning in Computer Science. International Society of the Learning Sciences, Inc.[ISLS].

Programaê. Disponível em <http://programae.org.br/>. Acesso em 30 de set. 2019.

Projeto Unisc Inclusão Digital. Disponível em $<$ http://projetouid.weebly.com//>. Acesso em 30 de set. 2019.

RoPE. Disponível em <http://lite.acad.univali.br/pt/rope-brinquedo-de-programar/>. Acesso em 30 de set. 2019.

Run Marco. Disponível em <https://runmarco.allcancode.com/> Acesso em 30 de set. 2019.

Scratch. Disponível em $<$ https://scratch.mit.edu/>. Acesso em 30 de set. 2019.

Selby, C., \& Woollard, J. (2013). Computational thinking: the developing definition. Monograph (Project Report).

Sociedade Brasileira de Computação (2019). Diretrizes para ensino de Computação na Educação Básica. Disponível em <http://sbc.org.br/documentos-da-sbc/send/131curriculos-de-referencia/1177-diretrizes-para-ensino-de-computacao-na-educacaobasica $>$. Acesso em 30 de set. 2019.

The New York Times (2019). 'Knitting Is Coding' and Yarn Is Programmable in This Physics Lab. Disponível em <https://www.nytimes.com/2019/05/17/science/mathphysics-knitting-matsumoto.html $>$. Acesso em 30 de set. 2019.

Vicari, R. M., Moreira, A. F., \& Menezes, P. F. B. (2018). Pensamento computacional: revisão bibliográfica. Disponível em $<$ https://www.lume.ufrgs.br/bitstream/handle/10183/197566/001097710.pdf?sequence= $1 \&$ isAllowed $=\mathrm{y}>$. Acesso em 30 de set. 2019.

Wing, J. M. (2006). Computational thinking. Communications of the ACM, 49(3), 33-35. 